\title{
Water Saving by using Nanoparticles in Heavy Oil Reservoir through Thermal EOR Method:Special Pertaining to ZnO \& CuO
}

\section{Masoumeh Tajmiri*, Mohammad Reza Ehsani}

Department of Chemical Engineering, Isfahan University of Technology, Isfahan 84156-83111, Islamic Republic of Iran

Study Area: Isfahan, Iran.

Coordinates: $32^{\circ} 38^{\prime} \mathrm{N} ; 51^{\circ} 39^{\prime} \mathrm{E}$

Key words: Steam assisted gravity drainage, Viscosity reduction, Residual oil saturation

\section{$\underline{\text { Abstract }}$}

Freshwater plays an integral part in many operating processes from production, manufacturing to steam and power supply. There are often conflicting demands on water resources in areas where oil companies operate the available supplies of water may be over-stretched. In oil fields, the ratio-of-water-to-oil (WCUT\%) is mostly $95 \%$ or higher. When water availability is in scarce, the oil industry uses its practical expertise to help unearth and tap new sources of water. Nanotechnology is an essentially modern scientific field which is constantly evolving with commercial and academic interest. In this work, we seek to compare the unique potential of $\mathrm{ZnO}$ and $\mathrm{CuO}$ nanoparticles on reducing the residual oil saturation (SOR) and WCUT\% consumption which has been one of the major issues in the oil industry. In the first step, laboratory tests were fulfilled in three phases, one phase without nanoparticles and two phases with two types of nanoparticles conditions, through scaled SAGD cell. Results show that the ultimate oil recoveries increase from $52.43 \%$ to 87.93 while without nanoparticles condition and $80.027 \%$ of OOIP whereas water consumption was alleviated to 20.3 and $12.5 \%$ by adding $\mathrm{ZnO}$ and $\mathrm{CuO}$ nanoparticles respectively. In the second step by using CMG software the proposed experimental model was simulated. From the results, we have been able to corroborate this fact that both nanoparticles cause to decrease water consuming whereas heavy oil recovery def initely raised.

in nanotechnology optimised products and processes for energy production and storage. These are currently in the development phase and are slated to contribute signif icantly to climate protection and solving our energy problems in the future (Shah, 2009).

Steam Assisted Gravity Drainage (SAGD) has several benefits compared to other thermal ones. In SAGD process, oil is drained with a flow approximately parallel to the steam chamber consequently arriving at the producer well still warm with high mobility (Butler \& Stephens, 1981; Butler \& Mokrys, 1991). Heavy oil viscosity is further reduced when metal is added (Clark et al., 1990). The mechanism of activity, selectivity and stability of nanoparticles in the dehydrogenation of cyclohexane and methylcyclohexane process have already been reported certain fields of application. High hopes are being placed

*Corresponding Author: maral.tajmiri@gmail.com 
(Cacciola et al., 1993). The viscosity and molecular weight of heavy oil Liaohe oilfield decrease in the steam stimulation process have been studied. This reduction happens from 88.5 to $55.8 \mathrm{~Pa}$.s, in $36.9 \mathrm{wt} \%$ reservoir rock (Fan, 2004). The micron-sized iron particles influence on heavy oil viscosity has been investigated without heating process. It is signif icantly showed that viscosity reduction is happened by iron particles (Hascakir et al., 2008). Ionic liquid has been applied to decrease viscosity, average molecular weight and asphaltene content of the heavy oil. The results show that weak bond formation between the ionic liquids and organic sulphur in heavy oil are the main cause of viscosity reduction (Fan et al., 2007). Solid particles effect such as copper and zinc on thermal conductivity improving liquid such as water have been shown. The main reason for this event is related to nanoparticles effect on transport properties and heat transfer ability (Li et al., 2009). Nanoparticles have been used to study the catalytic aqua-thermolysis behaviour of heavy oil. It is showed that adding $\mathrm{SiO}_{2}$ nanoparticles cause to reduce the hysteresis of both oil and water phases and the hysteretic behaviour of relative permeability curves (Clark et al., 1990). It has been identified that the rock pores may contain trapped oil, gas and water. Nanoparticles can be used to recover more residual oil. It is showed that nanotechnology effects on several parameters such as oil viscosity reduction (Fletcher \& Davis, 2010). The high surface-to-volume ratio of nanofluids has been reported to improve thermal properties. The surface-to-volume ratio of nanoparticles may be 1000 times greater than microparticles. A variety of particle sizes and types are tested to find the best particle suites for plugging the rock pores, which turns out to be elastic nanoparticles made of polymer threads that retract into coils. Nanoparticles in solid form such as silica are less effective (Kong \& Ohadi, 2010).

It has been seen that when nanoparticles enhanced water reaches towards the tunnel opening, it would accelerate faster than the particles behind to accumulate and plug the tunnel entrance and ultimately, sealing the tunnel. This forces the following water to take other paths through the rock's pores and passages, which is forced out with water flow. The result is that more oil extracts from the production well and higher profits for the petroleum companies (Skauge et al., 2010). Nano-sized metal effects to decreasing viscosity which has been investigated through a thermal process. The results provide a good understanding in viscosity reduction mechanism using metal nanoparticles at room temperature. It is reported that the reduction would be increased by applying steam stimulation due to the stronger effect on the aquathermolysis reactions. It is found that metal particles are applied as a catalyst. The concentration, size and type of particles are critical factors in reducing the viscosity
(Shokrlu \& Babadagli, 2010). It has been shown that nanofluid distributes through porous media by several mechanisms. It is found that the wettability of rock may be changed by absorption of nanoparticles on the rock surface. It is reported that absorption of nano silica particle concentration on the rock surface decreases silica particle concentration in the reservoir. Van der Waals attraction between the silica particle and the pore wall is the main reason of detaching on it. This is what causes the attractive forces between nanoparticles atoms and the pore wall (Caldelas et al., 2011). It has been found that by intensifying the particles repulsive forces, the stability and aggregation of suspensions could be avoided (Yu \& Xie, 2012). Hydrophilic or hydrophobic monolayer role of Silica nanoparticles fluid in water-wet sandstone in the pore spaces have been studied. It was found that the adsorption of SNPs can help to alter reservoir wettability (Hendraningrat \& Shidong, 2012). Different nanoparticles types have been used to alter the wettability through chemical interactions in interfacial tension (Ogolo et al., 2010). The effect of different compounds including alumina oxide and iron oxide have been investigated. Generally, the best results of wettability alteration to more water wet are due to alumina oxide through changing the contact angle of the fluids and phase behaviour (Ayatollahi \& Zerafat, 2012). $\mathrm{SiO}_{2}$ nanoparticles have been suggested to decrease the hysteresis behaviour of both oil and water phases and the hysteretic behaviour of relative permeability curves (Parvazdavani et al., 2012). The potential enhanced oil recovery of nano fluids have been shown $4-5 \%$ increasing recovery compared to brine in the core flooding procedure. The experimental results show that the IFT between the water phase and oil phase can be reduced by nano fluids and the wettability of solid surface alters to more water wet. It shows that releasing oil drops by increasing capillary pressure is completely obvious ( $\mathrm{Li}$ et al., 2013). Nano-size metal particles have been applied to reduce the viscosity of heavy oil/bitumen through steam injection. The experiments are a good proof of viscosity reduction by adding metal particles. The optimal concentration of metal particles is critical factors to influence on viscosity reduction (Shokrlu \& Babadagli, 2014).

The remarkable influence of $\mathrm{Fe}_{2} \mathrm{O}_{3}$ on viscosity reduction and concomitantly the increment in oil recovery has been found where experiment time becomes shorter through steam injection process (Afzal et al., 2014). The capability of ferrofluid have been investigated on overcoming of capillary pressure, expel trapped oil and finally enhance oil recovery numerically (Soares et al., 2014). Nanoparticle-based EOR application in wettability alteration, oil viscosity reduction of foam or emulsions stabilisation and interfacial tension decrease have been discussed. It is suggested that nanoparticles can be used as 
inhibiting hydrate and wax deposition (Bennetzen \& Mogensen, 2014). The dangerous effect of the usage and disposal of the spent nanoparticles have been studied on the environmental risks, human and animal health in oil and gas fields by considering the importance of nanotechnology application in the future (Amarfio \& Mohammed, 2014).

The potential of $\mathrm{ZnO}$ nanoparticles has been investigated to alter the wettability for both sandstone and carbonate cores in the heavy oil reservoir. It is completely obvious from relative permeability curves, $\mathrm{ZnO}$ nanoparticles shift the crossover point, critical saturation, end point of water and end point of oil to the rightward which means that the wettability alters to more water wet area (Tajmiri et al., 2015). The probable mechanism of four different hydrophilic silica nanoparticles has been studied to disperse in porous media, expel oil and enhance oil recovery through flooding method in Egyptian sandstone formation. The results revealed that silica nanoparticles were the main reason for increased oil recovery from 36 to $65 \%$ of the IOIP (El-Diasty, 2015). Reversible and irreversible adsorption mechanism have been investigated through porous media. Nanoparticles dispersion mechanism depends on several parameters such as nanoparticle type, the condition of dispersion, injected nanoparticles concentration, porous media and flow rate (Zhang et al., 2015). The transportation and distribution mechanism of $\mathrm{Al}_{2} \mathrm{O}_{3}, \mathrm{TiO}_{2}$, and $\mathrm{SiO}_{2}$ metal oxide nanoparticles have been studied through porous media. It is shown that nanoparticles cause higher oil mobility and higher oil recovery (Bayat \& Junin, 2015).

To maximise WCUT\% reduction due to nano-EOR, it is crucial to have a clear depiction of some parameters which are influencing. In this paper, water consumption by $\mathrm{ZnO}$ and $\mathrm{CuO}$ nanoparticles have been highlighted for a particular recovery process and heavy oil system at high temperature. Both oil recovery and WCUT\% have been discussed thoroughly.

\section{Employed methodology:}

ZnO \& CuO Nanoparticles to Reduce Water Consuming Heavy Oil Reservoir: as shown in Figure-1, 2-dimensional sand pack model $\left(20 \mathrm{X}_{2} \mathrm{o} \mathrm{X}_{4} \mathrm{~cm}^{3}\right)$ is employed for these studies (Tajmiri et al., 2015; 2016). An Iranian heavy oil is used for the studies along with distilled water having a viscosity of 1cp at ambient condition spent as base-fluid. Heavy oil properties are listed below and Nanoparticles specifications is in Table-1.

Properties of the oil used: Name- Kohe Mond; Oil density- 13API; Dead oil viscosity (at 7.158)- 160oo cp; Compressibility- $4.6710^{-6} \mathrm{psi}^{-1}$; Thermal expansion factor (from 4 to $\left.12.421^{\circ} \mathrm{C}\right)-4.0010-4\left({ }^{\circ} \mathrm{C}^{-1}\right)$.
Table-1: Specifications of nanoparticles used

\begin{tabular}{lllllll}
\hline $\begin{array}{l}\text { Particle } \\
\text { type }\end{array}$ & Formula & Form & $\begin{array}{l}\text { Purity } \\
(\%)\end{array}$ & $\begin{array}{l}\text { APS }^{*} \\
(\mathrm{~nm})\end{array}$ & $\begin{array}{l}\text { SPS }^{* *} \\
\left(\mathrm{~m}^{6} \mathrm{~g}^{-1}\right)\end{array}$ & Appearance \\
\hline $\begin{array}{l}\text { Zinc } \\
\text { oxide }\end{array}$ & $\mathrm{ZnO}$ & $\begin{array}{l}\text { Nano } \\
\text { powder }\end{array}$ & 99 & $<50$ & $>60$ & $\begin{array}{l}\text { White } \\
\text { powder }\end{array}$ \\
$\begin{array}{l}\text { Copper } \\
\text { oxide }\end{array}$ & $\mathrm{CuO}$ & $\begin{array}{l}\text { Nano } \\
\text { powder }\end{array}$ & 99 & $<50$ & $>60$ & $\begin{array}{l}\text { Black } \\
\text { powder }\end{array}$ \\
\hline *Absolute particle size; & ${ }^{* *}$ Specific surface area
\end{tabular}

Adopted experimental procedure: the model was assembled in which the major characteristics were; porosity, absolute permeability and pore volume of a packed model. The specific measurements are as given below. In witness experiment, the packed model saturated with oil and consequently SAGD experiment is usually implemented.

Properties of packed model used: Absolute permeability- $4.87 \mathrm{D}$; Porosity- 34\%; horizontal permeability/verticle permeability-1; Initial oil saturation-100\%; Initial water saturation-o\%.

For the experiment with nanoparticles, the model is first of all cleaned, the pore space of packed model is made vacuumed, the nanoparticles are flooded to packed model, the packed model is dried and then saturated with heavy oil. The physical model is usually made up of stainless steel with operating pressure up to 10ooopsi and operating temperatures up to $500^{\circ} \mathrm{C}$. The physical model and measurement tools placed in a thermostatic oven as shown by dotted line in Figure-2. In each experiment, the oven temperature kept fixed at $75^{\circ} \mathrm{C}$ and the system is allowed to reach thermal equilibrium. When the system avail the steady state, oven and steam generation temperature and pressure injection are set and water get steam in vent tube. The Mixture of heavy oil and produced condensate water are collected in a sample bottle at every 15 minutes. The oil and emulsion heated at $60^{\circ} \mathrm{C}$ in the oven for $24 \mathrm{~h}$ to break emulsion into oil and water and lately used centrifuged at 6oooRPM speed to separate the water and oil completely and the amount of separated oil is measured. The fluid cooled in a condenser before collection.

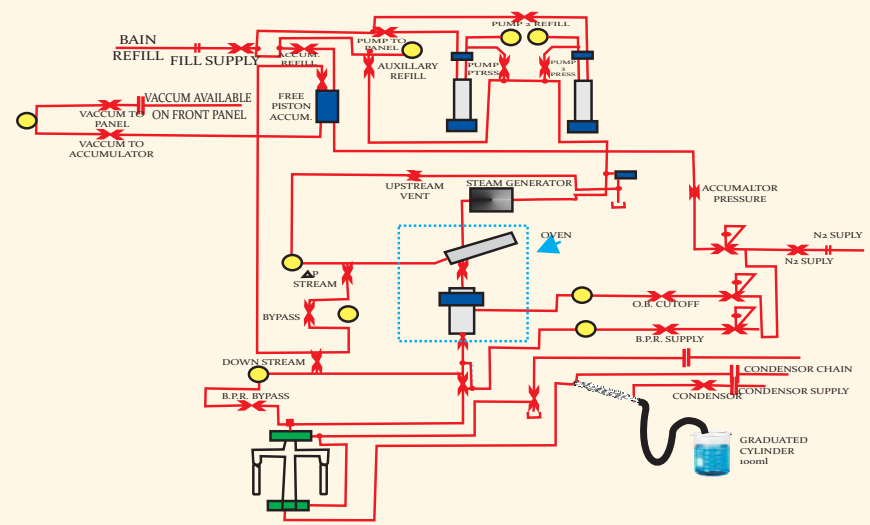

Figure-1: Schematic of experimental apparatus 


\section{Obtained outputs:}

Table - 2 and Figure-2 show the influence of $0.2 \mathrm{wt} \%$ of nanoparticles concentration of $\mathrm{ZnO}$ and $\mathrm{CuO}$ respectively on viscosity reduction at different temperature. As it has already been established that by increasing the temperature the viscosity decreases, one of the main reason of such consequence is the high thermal conduction capability of both nanoparticles, as by raising the temperature, this feature is encouraged.

Catalytic characteristics of nanoparticles on breaking the carbon and sulphur bonds in a chemical reaction were presumed to be the major cause of this event. It can be corroborated that asphaltene molecules in oil agglomerate consist of micelle like a cluster. By breaking the bonds between agglomerates, the viscosity could be reduced. Hence, nanoparticles get stuck between the oil layers and the exothermic chemical reaction between nanoparticles and oil phase provides the required energy to break big molecules bonds, such as asphaltene. Therefore, it seems that decreasing nano concentration plays a crucial role in cracking the heavy oil samples to the lighter components. Conclusively, as shown in Figure-2, $\mathrm{ZnO}$ nanoparticles plays a noticeable effect on viscosity reduction in comparison with $\mathrm{CuO}$ nanoparticles.

Table: 2 . Oil viscosity at various temperature with and without nanoparticles of $\mathrm{ZnO}$ and $\mathrm{CuO}$

\begin{tabular}{llll}
\hline Temperature & Oil Viscosity & $\begin{array}{l}\text { Oil Viscosity } \\
0.2 \% \mathrm{wt} \mathrm{ZnO}\end{array}$ & $\begin{array}{l}\text { Oil Viscosity } \\
0.2 \% \mathrm{wt} \mathrm{CuO}\end{array}$ \\
\hline $40^{\circ} \mathrm{C}$ & $620 \mathrm{cp}$ & $175.7 \mathrm{cp}$ & $201.2 \mathrm{cp}$ \\
$60^{\circ} \mathrm{C}$ & $265 \mathrm{cp}$ & $106.6 \mathrm{cp}$ & $110.2 \mathrm{cp}$ \\
$80^{\circ} \mathrm{C}$ & $100 \mathrm{cp}$ & $58 \mathrm{cp}$ & $45.2 \mathrm{cp}$ \\
$100^{\circ} \mathrm{C}$ & $63.25 \mathrm{cp}$ & $37.21 \mathrm{cp}$ & $29.46 \mathrm{cp}$ \\
\hline
\end{tabular}

The first experiment with a vertical distance between the horizontal well pair of $15 \mathrm{~cm}$ was done without nanoparticles condition. The oil recovery is shown in Figure-3. It took much time to penetrate the steam into the heavy oil layer. Over time, more area of heavy oil heated by steam and got mobile. The ultimate oil recovery was $52.43 \%$ after 690 minutes. The nanoparticles effect becomes sensible when steam adds to the system. As shown in Figure-3, the effect of nanoparticles on decreasing oil viscosity become sensible which help to raise oil recovery as compared to the previous experiment. The ultimate oil recovery was $87.93 \%$ of OOIP for $\mathrm{ZnO}$. As shown in Figure-2 $\mathrm{CuO}$ as $\mathrm{ZnO}$ nanoparticles reduces viscosity. Hence, when steam injection adds to heavy oil and nanoparticles, viscosity reduction happens more. It is clear from Figure-3, the effect of $\mathrm{CuO}$ nanoparticles on decreasing oil viscosity and raising oil recovery was less than ZnO. Therefore, the ultimate oil recovery was $80.027 \%$ of OOIP at 540 minutes of an experiment.

These results alluded that adding nanoparticles had the remarkable effect on declining the SOR; $\mathrm{CuO}-25 \%$;
$\mathrm{ZnO}-15 \%$ whereas $60 \%$ when without nanoparticles. The $\mathrm{ZnO}$ nanoparticles based upon its high thermal conductivity on transferring the heat to the oil revealed the better effect on viscosity reduction while comparison with $\mathrm{CuO}$ nanoparticles.

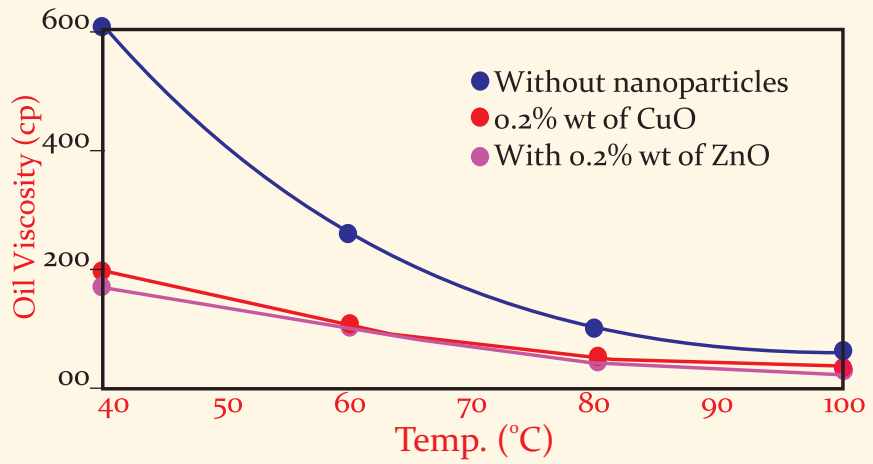

Figure- 2: The effect of nanoparticles on heavy oil viscosity

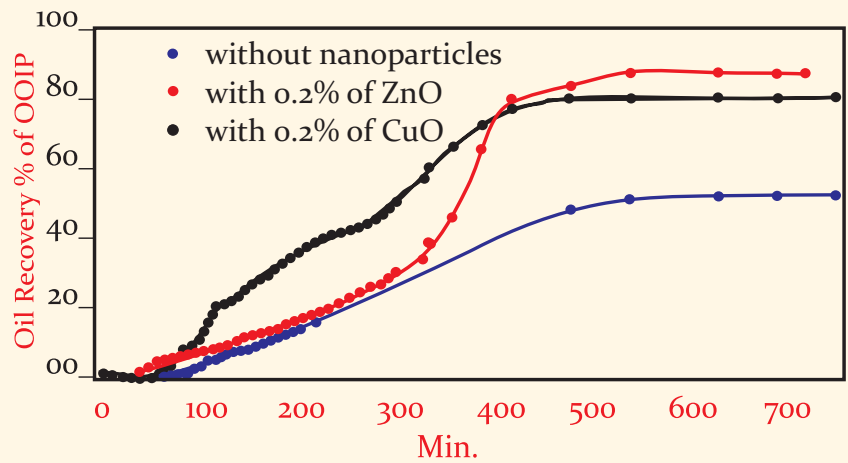

Figure:3. Oil recovery for from $\mathrm{ZnO} \& \mathrm{CuO}$

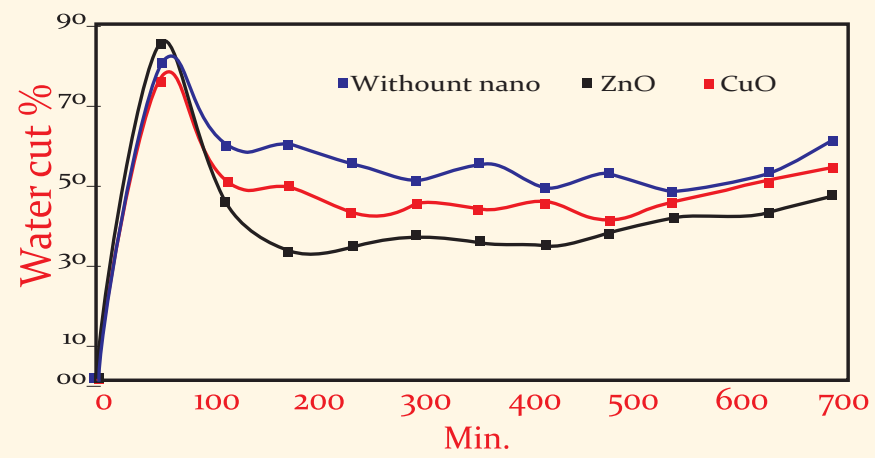

Figure-4: Influence of $0.2 \%$ wt of nanoparticles on WCUT\%

The influence of $0.2 \%$ wt of nanoparticles according to witness experiment without nanoparticles on WCUT\% is shown in Figure-4. At beginning of each test, the consumption of water based upon generating and affection the steam in all direction was high. The maximum WCUT\% happen at 60 minutes of the experiment. After this time for all experiment, this index decreases to $\mathrm{CuO}-54.89$; $\mathrm{ZnO}-50.01$ and 62.73 without nano. Ultimately nanoparticles indicated an evident influence on reducing the water content about 20.3 and $12.5 \%$ for $\mathrm{ZnO}$ and $\mathrm{CuO}$ nanoparticles, respectively while 
compared to without nanoparticles experiment.

A fabricated numerical modeling was used which was a commercial fully implicit thermal reservoir simulator, Computer Modeling Group (CMG) STARS 2007. It was a simplified single well pair 3-D model based on an experimental model. The model was set to be homogenous and SAGD mechanism is a symmetrical process. The model size was $\left(20 \mathrm{X}_{2} \mathrm{oX} 4 \mathrm{~cm}^{3}\right)$ and it was represented with the Cartesian grid blocks of size $1^{*} 1^{*} 1 \mathrm{~cm}$ directions, respectively. Figure-5 displays a $3-\mathrm{D}$ view of the reservoir model.

The final result of simulated cumulative water production for three phases; without nano, $\mathrm{ZnO}$ and $\mathrm{CuO}$ were $\mathrm{ZnO}-2400$; $\mathrm{CuO}-1176$ and 9825.03 when without any nanoparticle. As shown, by using the nanoparticles, the water consumption 24 and $11.96 \%$ were decreased for $\mathrm{ZnO}$ and $\mathrm{CuO}$, respectively. The results were obtained from CMG software confirmed that using nanoparticles could be a def initive reason to alleviate the water consumption.

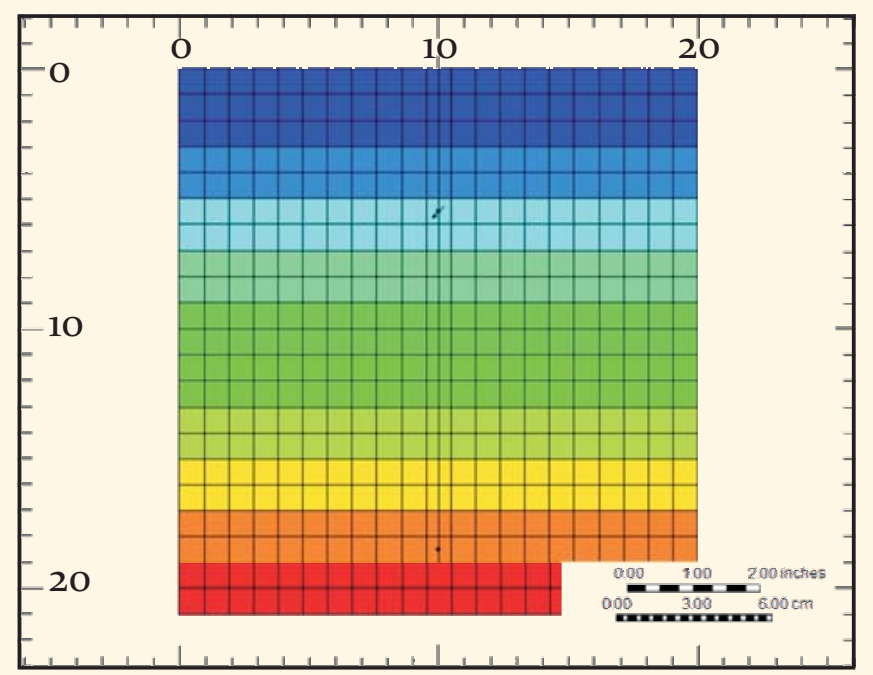

Figure-5: A view of the reservoir model

\section{Conclusion:}

In this review, the results obtained on water consumption reduction by $\mathrm{ZnO}$ and $\mathrm{CuO}$ nanoparticles experimentally and simulating by CMG Software has been compared. This issue happened when heavy oil recovery is increased which is a common phenomenon for the oil industries. The experiments were done through one of the substantial EOR processes which named SAGD. The water consumption in EOR process is high and the results of such studies could be applicable to heavy oil industry. The experimental and simulated results show that $\mathrm{ZnO}$ and $\mathrm{CuO}$ nanoparticles can penetrate into the oil molecules and break them into lighter components. Accordingly, the viscosity is decreased and the amount of water which need to use in order togenerate steam is phenomenally reduced.

\section{References:}

Amarfio, E.M, \& Mohammed, S. (2014), Environmental and health impacts of nanoparticles application in our oil industry. SPE Nigeria Annual International Conference and Exhibition. Lagos, Nigeria. doi.org/10.2118/172427-MS

El-Diasty, A.I. (2015), The potential of nanoparticles to improve oil recovery in Bahariya formation, Egypt: An Experimental Study. SPE Asia Pacific Enhanced Oil Recovery Conference, Kuala Lumpur, Malaysia, doi.org/10.2118/174599-MS

Afzal, S., Nikookar, M., Ehsani, M.R. \& Roayaei, E. (2014), An experimental investigation of the catalytic effect of $\mathrm{Fe}_{2} \mathrm{O}_{3}$ nanoparticle on steam injection process of an Iranian reservoir. Iran. J. Oil Gas Sci. Technol., 3(2):27-36.

Ayatollahi, S. \& Zerafat, M.M. (2012): Nanotechnology- assisted EOR technique, new solutions to old challenges. SPE International Oilfield Nanotechnology Conference. Noordwijk, Netherlands. doi.org/10.2118/157094-MS

Shokrlu, Y.H. \& Babadagli, T. (2014): Viscosity reduction of heavy oil/bitumen using micro- and nano-metal particles during aqueous and non-aqueous thermal applications. J. Petro. Sci. Eng., 119:210-220

Bennetzen, M.V. \& Mogensen, K. (2014): Novel applications of nanoparticles for future enhanced oil recovery. International Petroleum Technology Conference.Kuala Lumpur, Malaysia, doi.org/10.2523/IPTC-17857-MS

Butler, R.M. \& Stephens, D.J. (1981): The gravity drainage of steamheated heavy oil to parallel horizontal wells. L.Can.Petro. Technol., 20(2):90-96.

Butler, R.M. \& Mokrys, I.J. (1991): A new process (VAPEX) for recovering heavy oils using hot water and hydrocarbon vapor. J. Can. Petro. Technol., 30(1): 97-106.

Cacciola, G., Aristov, Yu.I., Restuccia, G. \& Parmon, V.N. (1993): Influence of hydrogen-permeable membranes upon the efficiency of the high-temperature chemical heat pumps based on cyclohexane dehydrogenation-benzene hydrogenation reactions. Int. J. Hydro. Ene. 18(8):673-68o.

Caldelas, F.M., Murphy, M., Huh, C. \& Bryant, S.L. (2011): Factors governing distance of nanoparticles propagation in porous media. Annual Production and Optimization Symposium. Oklahoma City, Oklahoma, USA. doi.org/10.2118/142305-MS

Clark, P.D., Clarke R.A., Hyne J.B. \& Lesage K.L. (1990): Studies on the effect of metal species on oil sands undergoing steam treatments. AOSTRA, J. Res., 6(1):53-64.

Bayat, A.E. \& Junin, R. (2015): Transportation of metal oxide nanoparticles through various porous media for enhanced oil recovery, SPE Asia Pacific Oil \& Gas Conference and Exhibition. Nusa Dua, Bali, Indonesia. doi.org/10.2118/176365-MS

Fan, H., Zhang, Y. \& Lin, Y.(2004): The catalytic effects of minerals on aqua- thermolysis of heavy oils. Fuel, 83(14-15), 2035-2039.

Fan, H, Li, Z-b. \& Liang, T. (2007): Experimental study on using ionic liquids to upgrade heavy oil. L.Fuel Chem. Technol. 35(1): 32-35.

Fletcher, A, \& Davis, J. (2010): How EOR can be transformed by nanotechnology. SPE Improved Oil Recovery Symposium, Tulsa, Oklahoma, doi.org/10.2118/129531-MS.

Shokrlu, Y.H. \& Babadagli, Y. (2010): Effect of nano sized metals on viscosity reduction of heavy oil/bitumen thermal applications. Canadian Unconventional Resources \& International Petroleum Conference, Calgary, Alberta, 
Canada, CSUG/SPE 137540.

Hascakir, B., Babadagli, T. \& Akin, S. (2008): Experimental and numerical modeling of heavy oil recovery by electrical heating. International Thermal Operations and Heavy Oil Sym posium, Calgary, Alberta, Canada. doi.org/10.2118/117669-MS

Hendraningrat, L., \& Shidong, L. (2012): A glass micro model experimental study of hydrophilic nanoparticles retention for EOR project. SPE Russian Oil and Gas Exploration and Production. Technical Conference and Exhibition. Moscow. Russia. doi.org/10.2118/159161-MS..

Li, S., Hendraningrat, L. \& Torsaeter, O. (2013): Improved oil recovery by hydrophilic silica nanoparticles suspension: 2Phase Flow Experimental Studies. International Petroleum Technology Conference. Beijing, China. doi.org/10.2523/IPTC-16707-MS

Kong, X., \& Ohadi, M. (2010): Application of micro and nano technologies in the oil and gas industry an over view of the recent progress. International Petroleum Exhibition \& Conference held, Abu Dhabi, Emirate. doi.org/10.2118/138241-MS

Li, Y., Zhou, J., Tung, S., Schneider, E. \& Xi, S. (2009): A review on development of nano fluid preparation and characterization, Powder Technol., 196(2), 89-101.

Ogolo, N.A, Olafuyi, O.A. \& Onyekonwu, M.O. (2010): Enhanced oil recovery using of nano particles. SPE Saudi Arabia Section Technical Symposium. Al-Khobar, Saudi Arabia. doi.org/10.2118/160847-MS

Parvazdavani, M., Masihi, M., Ghazanfari, M.H. \& Mashayekhi , L. (2012): Investigation the effect of water based nanoparticles addition on hysteresis of oil and water relative permeability curves. SPE International Oilfield Nanotechnology Conference, Noordwijk, Netherlands. doi.org/10.2118/157005-MS
Soares, F.S.M.A., Prodanoviæ, M. \& Huh, C. (2014): Excitable nanoparticles for trapped oil mobilization. SPE Improved Oil Recovery Symposium. Tulsa, Oklahoma, USA. doi.org/10.2118/169122-MS

Shah, R.D., (2009): Application of nanoparticle saturated injectant gases for EOR of heavy oils. SPE Annual Technical Conference and Exhibition. New Orleans, Louisiana. dx.doi.org/10.2118/129539-STU

Skauge, T., Spildo, K. \& Skauge, A. (2010): Nano- sized particles for EOR. SPE Improved Oil Recovery Symposium. Tulsa, Oklahoma, USA. doi.org/10.2118/129933-MS

Tajmiri, M., Mousavi, S.M., Ehsani, M.R., Roayaei, E. \& Emadi, A. (2015): Wettability alteration of sandstone and carbonate rocks by using $\mathrm{ZnO}$ nanoparticles in heavy oil reservoirs. Iran. J. Oil Gas Sci. Technol., 4(4):50-66.

Tajmiri, M, \& Ehsani, M.R., (2016): The Potential Of $\mathrm{CuO}$ Nanoparticles to Reduce Viscosity and Alter Wettability at Oil- Wet and Water- Wet Rocks in Heavy Oil Reservoir. SPE Annual Technical Conference and Exhibition, Dubai, UAE. doi.org/10.2118/181298-MS.

Yu, W., \& Xie, H. (2012), A review on nano fluids: preparation, stability mechanisms and applications. Journal of Nano Materials, Article ID 435873.

Yu, W, \& Xie, H. (2012), A review on nano fluids: preparation, stability mechanisms and applications. L.Nanomater., Article ID 435873 .

Zhang, T., Murphy, M.J., Yu, H., Bagaria, H.G., Yoon, K.Y., Nielson, B.M., Bielawski , C.W., Johnston, K.P., Huh, C. \& Bryant, S.L. (2015): Investigation of nanoparticle adsorption during transport in porous media, SPE Journal, 2o(4), doi.org/10.2118/166346-PA 